\title{
Opinions towards the water-related Payments for Ecosystem Services (PES) schemes: The stakeholders' point of view
}

\author{
Alessandro Paletto ( $\sim$ alessandro.paletto@crea.gov.it) \\ Council for Agricultural Research and Economics https://orcid.org/0000-0001-8708-3723
}

\section{Klára Báliková}

Technicka Univerzita vo Zvolene

Isabella De Meo

Council for Agricultural Research and Economics

\section{Research}

Keywords: Sustainable forest management, payments for water ecosystem services, stakeholders' involvement, questionnaire survey, Italy

Posted Date: April 16th, 2020

DOI: https://doi.org/10.21203/rs.3.rs-22143/v1

License: (9) This work is licensed under a Creative Commons Attribution 4.0 International License. Read Full License

Version of Record: A version of this preprint was published at Water and Environment Journal on March 1st, 2021. See the published version at https://doi.org/10.1111/wej.12697. 


\section{Abstract}

Background: Forests provide a wide range of water-related ecosystem services (WES) vital for human well-being such as groundwater recharge, runoff and water discharge to streams, soil erosion protection, aesthetic landscape and recreational opportunities. Sustainable forest management and afforestation/reforestation practices can maintain and improve the long-term provision of WES. In this context, new market-based mechanisms - Payments for Ecosystem Services (PES) - can promote sustainable forest management by reducing negative externalities. To implement PES schemes for WES, many stakeholders with different knowledge, interests, and needs must be consulted and involved in the design and implementation process.

Methods: The aim of this study is to investigate stakeholders' opinions on the relationships between forests and water resources and the water-related Payments for Ecosystem Services (PES) schemes in Italy. A semi-structured questionnaire was administered by email to 39 stakeholders identified through a stakeholder analysis. The stakeholders were classified in four groups: buyers ( $15.4 \%$ of stakeholders), sellers (15.4\%), intermediaries (43.6\%), and knowledge providers (25.6\%).

Results and conclusions: The results show that the three most important WES provided by forests are soil erosion reduction, followed by provision of habitats for different species and surface runoff reduction. The respondents emphasize the importance of regulating and supporting services, while they minimize the importance of cultural services. For the sample of respondents, market-based instruments have an efficiency comparable to regulatory instruments, but a shared value for ecosystem services among stakeholders is required in the implementation of PES schemes. According to respondents' opinions, the public authority should play the role of both buyer and regulator, while the other stakeholders should be consulted (citizens) or actively involved (farmers' and forest owners' associations) in the decision-making process related to the PES schemes.

\section{Background}

In the last decades, many studies have highlighted that the management and mismanagement of forests affects the hydrological cycles and outcomes (Wunder and Thorsen 2014; Leonardi and Pettenella 2018). In the international scientific literature, the hydrological outcomes useful to human beings are defined as water-related ecosystem services (WES) and they can be classified in four main categories (Hanson et al. 2011): water flow regulation, water purification, soil erosion control, and freshwater supply. Particularly, forests influence stream discharge, precipitation, evapotranspiration, infiltration, groundwater recharge, freshwater flows regulation, erosion control and soil protection, and streambank stabilization (Saenz and Mulligan 2013; Birgé et al. 2016; Esse et al. 2019). Sustainable forest management (SFM) - as well as afforestation and reforestation practices - can be considered important instruments to enhance and protect WES (Nisbet et al. 2011; Pukkala 2016). SFM can have a positive impact on water quality and quantity in rivers and streams because intensive management practices - e.g., increased forestry machine traffic, site preparation, stump harvesting - reduce water quality, while over-utilisation, land-use 
change, and use of exotic species lead to unwanted changes in soil and water quantity and quality (Kneeshow et al. 2000; Stupak et al. 2011). Conversely, afforestation and reforestation practices have a positive impact on a wide variety of water-related issues such as reducing river flooding, landslides, salinity, soil erosion, and water pollutant loads (Huang et al. 2003; van der Salm et al. 2006; van Dijk and Keenan 2007).

At first, the key role of "well-managed" forests in the provision of WES has been recognised by scientific community, later also policy makers emphasized the importance of the relationship between forests and WES supply (Creed et al. 2018). As regards to the development of policies, the Shinga Declaration by International Expert Meeting on Forests and Water (2002) pointed out the need of an holistic approach to integrate people's needs in the forests and water management, while the 3rd World Water Forum (2003) helped drive the incorporation of biophysical interactions between forests and water resources into policy-making (Calder et al. 2007). In 2007, the Warsaw Resolution on "Forests and Water" - elaborated during the 5th Ministerial Conference on the Protection of Forest in Europe (MCPFE) - recognized the close relationship between forests and water. In addition, the Warsaw Resolution established to maintain and enhance the protective functions of forests for water and soil; to assess afforestation and reforestation programmes in terms of their effects on quality and quantity of water resources, flood alleviation and soil; to promote the restoration of degraded forests, particularly in floodplains and upper watershed areas for the benefit of the water environment, flood reduction, conservation of biodiversity and soil protection. Afterwards, the new European Union (EU) Forest Strategy (2013) acknowledged that forests mitigate the impact of extreme weather events by moderating temperatures, and reducing wind speed and water run-off. Therefore, the EU member states should maintain and enhance forest cover to ensure soil protection, water quality and quantity regulation by integrating sustainable forestry practices in the Programme of Measures of River Basin Management Plans under the Water Framework Directive (2000/60/EC) and in the Rural Development Programmes (2014-2020).

To facilitate the diffusion of best practices in forest management finalized to maintain and improve the provision of WES, some market-based mechanisms - e.g., Payments for Ecosystem Services (PES) have been developed and implemented (Smith et al. 2013; Pirard and Lapeyre 2014; Wunder 2015). PES can be defined as a transfer of resources between social actors, which aims to create incentives to align individual and/or collective land us decisions with the social interest in the management of natural resources (Muradian et al. 2010, p. 1205). A payment scheme for WES is a new way of using markets to ensure incentives for better natural resources management by reducing negative externalities (Diswandi 2017). The market-based mechanisms are used to shape decision-making over changes in land use and management that are critical to the sustainable use of watersheds (Smith et al. 2006). In the international literature, there are three types of payments for WES (Hanson et al. 2011): (1) voluntary payments by downstream entities to upstream landowners to decrease the costs of doing business; (2) payments made to minimize an entity's cost of meeting a regulation; and (3) payments made to generate public benefits. To implement these types of payments for WES, many stakeholders with different knowledge, interests, needs and perception of the current state of ecosystem services must be involved (Reed et al. 2017; Báliková et al. 2020). Stakeholders can be individuals, groups, and institutions/organizations from 
the market, governmental and civil society sector, such as landowners and farmers, state and regional agencies, private consultancy companies, not-for-profit Non-Governmental Organizations (NGOs) (Engel et al. 2008; Sattler et al. 2013). These stakeholders can be aggregated in four main groups involved in the design and implementation of the PES schemes: "sellers" or "providers" (everyone in the position to safeguard WES delivery), "buyers" (the direct beneficiaries of the provided WES), "intermediaries" (mediators involved in contract negotiation, collection and administration of payments, monitoring and verifying WES delivery); and "knowledge providers" (experts able to facilitate the dissemination of information and knowledge about PES schemes).

Starting from these considerations, the aim of the present study is to analyse Italian stakeholders' opinions concerning the relationships between forests and water resources and the potential development of PES schemes as tool aimed at improving the provision of water-related ecosystem services. All groups of stakeholders - "sellers", "buyers", "intermediaries", "knowledge providers" - were involved in the study in order to collect and analyse the different points of views. The study is developed in the context of COST Action CA15206 "Payments for Ecosystem Services - Forests for Water" (PESFORW) aimed to produce the state-of-the-art of PES and to improve European capacity to use PES in the context of water storage and water bodies' development.

\section{Materials And Methods}

The study was structured in four steps to investigate stakeholders' opinions towards interactions between forests and water resources: (1) literature review on PES in forestry, aimed to bring out the most important WES; (2) stakeholder analysis to identify a sample of stakeholders to involve in the survey; (3) development and administration of a semi-structured questionnaire; (4) processing of the collected data.

In the first step, a literature review was made with the aim to analyse the peer-reviewed publications (books, chapters of book, articles, and papers published in conference proceedings) concerning the PES schemes. A time period of 15 years (period 2005-2019) was considered to highlight the trend of PES issue within the scientific community. Firstly, the peer-reviewed publications on PES issue published in the above-mentioned period were identified using some main keywords ("Payment for Ecosystem Services", "forestry/forest", "water") in the Scopus database. The keywords were searched in the titles, abstracts and keywords of the individual articles, papers, chapters, and books. Secondly, the peer-reviewed publications identified were examined through a textual analysis to find out how many of these publications were related to the forestry sector in general, and in particular the relationship between forests and water resources. Thirdly, the textual analysis of publications made it possible to identify 10 WES included in the four main categories of ecosystem services in accordance with MEA (2005) and TEEB (2010) classification systems (Fig. 1): provisioning, regulating, supporting, and cultural services.

During the second step, a stakeholder analysis - an approach for generating knowledge about stakeholders to understand their behaviour, attitudes, inter-relations and interests (Varvasovszky and Brugha 2000; Paletto et al. 2015) - was performed. A database of forestry stakeholders previously 
developed in the ambit of two LIFE Programme projects was used to select the respondents to be involved in the survey. Then all stakeholders included in the database were contacted via email to request their availability to participate in the survey. In addition, the database was integrated through a snowball sampling method including additional stakeholders identified by respondents. Therefore, the results of this study cannot be considered representative of the WES stakeholder population, but only of the sample of Italian stakeholders. The stakeholders willing to participate in the survey were classified in four targeted stakeholders' groups (Sattler et al. 2013; Reed et al. 2017): "buyers" (public institutions, private companies, environmental NGOs), "sellers" (associations of farmers and forest owners), "intermediaries/brokers" (consulting companies and freelance), and "knowledge providers" (universities and research institutes).

In the third step, a first version of the semi-structured questionnaire was developed by the researchers involved in the study. The preliminary version of the questionnaire was pre-tested by two privileged stakeholders to understand the ease of filling the questionnaire and the clarity of the proposed questions. At the end of the pre-test stage, a couple of questions have been changed and simplified in accordance with the stakeholders' suggestions and comments. The final version of the questionnaire was formed by twenty questions, divided into four thematic sections (Annex 1): Sect. 1 "General and personal information"; Sect. 2 "Relationship between forests and water"; Sect. 3 "Payment for Ecosystem Services (PES) schemes"; Sect. 4 "Stakeholders' involvement in the PES schemes".

The first thematic section is formed by four open-ended questions: "Name of your organization" (Q1.1), "Region" (Q1.2), "Role of the respondent in their organization" (Q1.3), "Scientific field of the respondent" (Q1.4), and one closed-ended question: "Years of work in the scientific field" (Q1.5) using the following time classes: less than 1 year; $1-5$ years; $6-10$ years; $11-15$ years and more than 15 years.

The second thematic section is formed by four questions concerning the relationships between forests and water resources. The first question (Q2.1) investigates the importance of forests in providing 10 WES identified during the literature review: 1 - recharge of groundwater; 2 - provision of clean drinking water (provisioning services); 3 - buffering and filtering of pollutants; 4 - surface runoff reduction; 5 - soil erosion reduction; 6 - flooding risk protection (regulating services); 7 - provision of habitat for different spices; 8 maintenance of genetic diversity in water ecosystem (supporting services); 9 - provision of recreation and leisure activities of forests and water bodies; 10 - provision of scenic landscape of forests and water bodies (cultural services). The respondents assign the level of importance of each WES using a 5-point Likert scale format (from $1=$ very low importance to $5=$ very high importance). In the second question (Q2.2), the respondents compare the importance of each category of ecosystem service using a pairwise comparison method (Saaty 2003). The last two questions (Q2.3 and Q2.4) consider the stakeholders' perception towards trade-offs among WES related to the forest management practices (final felling and thinning) and afforestation/reforestation activities. The respondents' opinions about the potential tradeoffs between WES generated by forest management and afforestation/reforestation practices are collected using open-ended questions. 
The third thematic section considers the implementation of the PES schemes in Italy. In the first question (Q3.1), respondents compare the efficiency of the PES schemes with the use of regulation policy instruments (i.e. command-and-control policy). Command-and-control instruments are based on regulations that set ambient, emissions targets and which impose penalties if those standards are not complied with (Andersen and Sprenger 2000). Conversely, market-based instruments are based on price values or other economic values that can encourage actors to reduce environmental pollution or to improve natural resources management (Boisvert et al. 2013). In the second question (Q3.2), the level of importance of three aspects related to the implementation of PES schemes is investigated (Reed et al. 2017): (1) Multi-level governance (incorporating local and indigenous knowledge about ecosystem services and payment mechanisms in the decision-making process); (2) Shared values for ecosystem services (understanding the ecological and ethical values that can be shared by different groups within the society in relation to the natural environment); (3) Bundling or layering of services across the multiple scales (considering the trade-off between ecosystem services provided by forests). The third question (Q3.3) investigates respondents' opinions on environmental effectiveness of PES schemes defined as the change in provision of services included by the program in comparison with provision of ecosystem services without the PES schemes (Börner et al. 2017). The transaction and implementation costs, the direct and indirect effects are used as factors to determine the environmental effectiveness of the PES schemes. The respondents assign their preferences using a 5-point Likert scale format for Q3.2 and Q3.3 (from 1 = very low importance to $5=$ very high importance).

The fourth thematic section focuses on respondents' opinions about stakeholders' involvement in the PES schemes. The first question (Q4.1) considers the role of public authority distinguishing between four potential roles in PES design and development. According to Matzdorf et al. (2013), Leonardi and Pettenella (2018) the public authority can intervene both as buyer and/or as legal institution providing rules and obligations for the PES scheme design and development. In this study, the following governance models related to the role of public authority are considered: (1) payments for WES should be managed without any intervention from the public authorities; (2) public authority should be involved as a buyer; (3) public authority should be involved as a regulator; and (4) public authority should be involved both as buyer and as regulator. The first option is based on the Coasean approach where the contracts are negotiated by two private actors without any intervention from the public authority (Pascual et al. 2010). Conversely, the involvement of public authority as buyer in PES schemes correspond to the Pigouvian approach (Tacconi 2012) where public actors (e.g., municipalities) pay landowners - farmers and forest owners - to increase water quality within the water abstraction areas (Leonardi and Pettenella 2018).

The second question (Q4.2) considers the level of involvement of other stakeholders - single farmers and forest owners, environmental NGOs, tourism associations, farmers'/forest owners' associations, fishing associations, citizens - in the PES schemes design and development. The respondents assigned to each stakeholder the appropriate level of involvement using a five-point Likert scale format: 1 - Noninvolvement; 2 - Information; 3 - Consultation; 4 - Collaboration/Deliberation and 5 - Codecision/Coproduction. The four levels of involvement are characterized by a growing power in the hands 
of stakeholders and a simultaneous reduction in the number of people involved (Fig. 2). According to Herwig (2008) and Bréthaut (2016) information does not imply an active involvement of stakeholders in a decision-making process, but rather a desire of decision makers to inform them about what decision might be implemented. In the consultation, stakeholders provide information, needs, interests to the decision makers, but they not necessarily have an impact on the decision that might be implemented. In the collaboration/deliberation interests and arguments of stakeholders are taken into account and are integrated in the decision-making process, while in the co-decision/coproduction stakeholders actively take part in the decision-making process from defining alternatives to implementing the final decisions. However, an increased level of involvement can lead to a reduction in the number of stakeholders involved due to the necessary expenditure of material and non-material resources.

In the fourth step, data were processed to highlight the differences between targeted groups of stakeholders (buyers, sellers, intermediaries/brokers, knowledge providers) and between respondents belonging to different scientific fields and with different years of expertise. The answers to the openended questions (Q2.3 and Q2.4) were examined to find logical interpretations through a textual analysis, while the answers to the closed-ended questions were used to provide the main descriptive statistics (frequency distribution, mean, median, st.dev.). In addition, to define the hierarchical position of the WES within the four categories of ecosystem services (provisioning, regulating, supporting, and cultural services), the data collected with question Q2.2 were processed thought the Analytic Hierarchy Process (AHP) method. The AHP is a multiple-criteria decision making method used to rank the alternatives by taking into account the importance of the different criteria in order to facilitate decision-making for complex choices (Saaty 1987; Alonso and Lamata 2006). In the present study, the factor priority score ( $w$ ) - normalized Eigen vector of the comparison matrix - is used to define a ranking of the categories of ecosystem services. Within the categories of ecosystem services, the relative importance of the individual WES is calculated as mean value (data collected using the 5-point Likert scale format).

The Shapiro-Wilk test $(a=0.05)$ - aimed to compare the similarity between the observed and normal data distribution - shows a non-normal distribution of data. Therefore, the non-parametric tests of the KruskalWallis and Mann-Whitney were used to highlight the differences between groups of respondents.

The Kruskal-Wallis test $(a=0.05)$ - a non-parametric statistical test to assess the differences among three or more independently sampled groups on a single, non-normally distributed continuous variable was used to highlight differences between the four targeted groups of stakeholders and between different years of experience of respondents.

The Mann-Whitney test $(a=0.05)$ - a non-parametric statistical test to assess the differences between two independently samples groups - was used to point out differences between forestry stakeholders and stakeholders of other scientific fields (e.g., environmental and ecology sciences, hydrology and water resource management).

For statistical data processing, the XLStat 2017 software was used. 


\section{Results}

\section{Literature review}

The results of literature review show that the first publication on Payments for Ecosystem Services (PES) is dated 2005 (Salzman 2005), while the first publications of PES in forestry are dated 2007, with six peerreviewed publications. Within these six publications, one explores the possibilities of applying PES in sustainable land-use management in the Mountain Mainland Asia emphasizing the importance of WES (Sharma and Xu 2007).

In the period 2005-2019, 1,227 peer-reviewed publications on PES (on average 81.8 per year), 482 peerreviewed publications on PES in forestry (on average 32.2 per year), and 106 peer-reviewed publications on PES concerning forestry and water resources (on average 7.1 per year) have been published (Fig. 3). In the time period covered by the literature review, there is a growing trend with some interesting differences between the three 5-years-periods. Before 2014, the average publication growth (\%) year by year is + $137.9 \%$ for publications on PES, $+60.9 \%$ for publications on PES in forestry, and $+50.4 \%$ for publications on PES concerning forestry and water resources. In the period 2015-2019, the average publication growth (\%) year by year is $+7.5 \%$ for publications on PES, $+12.0 \%$ for publications on PES in forestry, and $+20.0 \%$ for publications on PES concerning forestry and water resources. Consequently, these results show an initial high publishing activity on PES (period 2007-2014), followed by a partial stabilization of the number of publications in the recent period 2015-2019. Probably, the future growing trend will be related to PES schemes implementation in different geographical contexts and scientific areas.

\section{Characteristics of respondents}

At the end of the data collection period, 39 stakeholders have completed the questionnaire, distributed in the four targeted groups (Table 1): 6 buyers (15.4\% of total respondents), 6 sellers (15.4\%), 17 intermediaries (43.6\%), and 10 knowledge providers (25.6\%).

Regarding the expertise of respondents, results show that the sample of stakeholders involved in the survey has a long field experience: $69.2 \%$ of respondents has more than 15 years-long experience in its professional field, $12.8 \%$ has a $11-15$ years-long expertise, while the remaining $18.0 \%$ has less than 11 years of experience.

The three scientific fields to which respondents belong are forestry ( $66.7 \%$ of total respondents), followed by environmental/ecology science (25.5\%) and water resource management (7.8\%).

\section{Relationship between forests and water resources}

The results (Q2.1) show that, for the majority of stakeholders, the most important category of WES is regulating services (priority score $w=0.3233$ ), followed by provisioning services $(w=0.2810)$ and supporting services $(w=0.2307)$. Conversely, cultural services are the category considered as less important $(w=0.1555)$. Within each category, results $(\mathrm{Q} 2.2)$ evidence the three most important individual 
WES are as follows (Fig. 4): soil erosion reduction (mean $=4.74, S D=0.72)$, provision of habitats for different species (mean $=4.56, S D=0.68)$, and surface runoff reduction (mean $=4.41, S D=0.82$ ). Conversely, the sample of respondents consider the two individual cultural services of marginal importance with respect to the other three categories: aesthetic value of landscape (mean $=4.00, S D=$ 0.92 ) and recreational opportunities (mean $=3.26, S D=1.08)$.

The average values for the four categories of ecosystem service are the following: regulating services (4.37), supporting services (4.36), provisioning services (4.14), and cultural services (3.63). Comparing the above average values with the priority scores assigned by respondents during the pairwise comparison to the four categories of ecosystem services (shown in Table 2), the only relevant difference is the highest value assigned to the provisioning services in the pairwise comparison. A hypothesis to explain this difference can be the possibility that - when thinking to the category of provisioning services - respondents have in mind some individual WES, different from those considered in the present questionnaire, that influence their opinion.

Observing the data by targeted group of stakeholders, results highlight that intermediaries and knowledge providers assign the highest level of importance to regulating services ( $w=0.3369$ and 0.3814 respectively), while provisioning services are the most important WES category for sellers $(w=0.3890)$. Buyers assign the same level of importance to provisioning and regulating services ( $w=0.2964$ for both). It is interesting to point out that for all targeted groups cultural services represent the less important WES category with the following priority scores: $w=0.1242$ for buyers, $w=0.1707$ for sellers, $w=0.1502$ for intermediaries, and $w=0.1720$ for knowledge providers. For all groups of stakeholders, the Consistency Ratio $(C R)$ is less than $0.05(5 \%)$.

The results for individual WES (Fig. 5) show that for buyers and intermediaries the most important WES is the soil erosion reduction (mean value 4.83 and 4.88 of respectively), while for knowledge providers is the provision of habitats for different species (4.70) and for sellers is the buffering and filtering of pollutants from surface waters (4.83). Besides, the importance of other WES provided is emphasized such as the groundwater recharge by intermediaries (4.65), the maintenance of genetic diversity in water ecosystem by knowledge providers (4.40), and the surface runoff reduction by buyers (4.67). However, despite these differences the non-parametric Kruskal-Wallis test $(\alpha=0.05$ with a $p$-value from 0.137 - surface runoff reduction and 0.857 - provision of habitats for different species) showed no statistically significant difference between the four groups of stakeholders for all WES considered.

When observing the results for the scientific field of respondents, the results show that for the forestry respondents the three most important WES are: soil erosion reduction (mean $=4.85, S D=0.37$ ), surface runoff reduction (mean $=4.54, S D=0.65$ ), and protection from the flooding risk (mean $=4.24, S D=1.01$ ). Conversely, for the non-forestry respondents the most important WES provided by forests are the provisioning of habitats for different species $($ mean $=4.85, S D=0.55)$, soil erosion reduction (mean = $4.54, S D=1.13)$, and groundwater recharge (mean $=4.31, S D=0.95)$. The Mann-Whitney non-parametric test showed a significant difference only for the provisioning of habitats for different species $(p=0.036$, 
$a=0.05$ ), with group of respondents with expertise in environmental/ecology sciences shown to consider more important the provision of habitat, compared to those specialized in forestry.

The results show that the number of years of expertise of respondents is a variable that can influence the ranking of WES provided by forests. The respondents with more than 15 years of experience emphasize the importance of two WES compared to other respondents: soil erosion reduction (mean $=4.85, \mathrm{SD}=$ 0.36 ) and surface runoff reduction (mean $=4.67, S D=0.55$ ). Conversely, the respondents with less than 5 years of experience assign a higher importance to groundwater recharge (mean $=4.67, S D=0.58$ ) and maintenance of genetic diversity in water ecosystem (mean $=5.00, S D=0.00)$. Nevertheless, the KruskalWallis non-parametric test showed statistically significant differences only for the surface runoff reduction ( $p=0.020, a=0.05)$.

\section{Trade-offs between water-related ecosystem services}

Concerning the questions about trade-offs between WES generated by forest management and afforestation/reforestation practices (Q2.3 and Q2.4), most of the respondents emphasize that afforestation/reforestation practices do not generate trade-offs between WES (76.9\% of respondents), while only $23.1 \%$ of respondents are of the same opinion for forest management practices (final felling and thinning).

According to respondents' opinions forest management practices can generate trade-off mainly between provisioning services and supporting services (50.0\% of affirmative responses to this question), followed by supporting services vs. cultural services $(41.7 \%)$ and provisioning services vs. regulating services (33.3\%).

Regarding the afforestation/reforestation practices, respondents evidence two mainly possible trade-offs: supporting vs. cultural services (55.5\% of affirmative responses to this question), and provisioning vs. supporting services (44.4\%).

\section{Payments for Ecosystem Services schemes}

Some interesting hints can be found in the results about respondents' perception of PES schemes efficiency compared to regulation policy instruments in protecting and sustaining WES (Q3.1). First of all, respondents show no clear preference for either of the two instruments compared: $35.3 \%$ consider PES schemes less efficient compared to the "command-and-control" instruments in order to protect WES, while $32.4 \%$ believe that PES schemes are more efficient compared to regulatory instruments.

Buyers and intermediaries are the groups that believe market-based mechanisms are more efficient than regulatory instruments $(50.0 \%$ and $43.8 \%$ respectively), while for sellers the regulatory instruments are more efficient than PES schemes (66.7\%) and for knowledge providers the two instruments have a similar efficiency in protecting WES.

When observing the data in relation to the years of expertise of respondents, results show that the majority of respondents with 11-15 years of expertise consider market-based mechanisms more efficient 
than regulatory instruments (50.0\%), while respondents with less than 5 years of expertise believe that regulatory instruments are more efficient $(100.0 \%)$.

Furthermore, when considering results for the scientific field of respondents, it is important to highlight that respondents of the forestry sector have more confidence in the efficiency of PES schemes than respondents of other scientific fields (water resource management and environmental/ecology sciences). In fact, the results show that $39.1 \%$ of forestry respondents and $16.7 \%$ of other scientific field respondents consider PES schemes more efficient than regulatory instruments.

The respondents' opinions about the level of importance of different key aspects related to the implementation of the PES schemes (multi-level governance, shared values, bundling or layering of services across multiple scales) (Q3.2), highlight that a shared value for ecosystem services between social actors is considered of great importance (mean $=4.38, S D=0.75)$. Multi-level governance aimed to incorporate local knowledge in the decision-making process has a value slightly lower (mean $=4.05, S D=$ $1.02)$, followed by bundling/layering of services across multiple scales (mean $=3.54, S D=1.05$ ).

The results show that all the groups of stakeholders consider the shared value for ecosystem services between social actors the most important aspect in the implementation of the PES schemes, with the following mean values (Fig. 6): 4.27 for buyers, 4.53 for intermediaries, 4.50 for knowledge providers, and 4.00 for sellers. With regard to the other two aspects, buyers and sellers emphasize the importance of bundling/layering of services across multiple scales (mean values of 3.67 and 4.00 respectively), while intermediaries and knowledge providers stress the importance of multi-level governance (mean values of 4.31 and 4.50 respectively).

However, the non-parametric Kruskal-Wallis test $(a=0.05$ with a $p$-value from 0.081 - multi-level governance to 0.626 - bundling/layering of services across multiple scales) showed no statistically significant difference between the groups regarding all the aspects related to the implementation of PES schemes.

When observing the data in relation to the years of expertise of respondents, results show that respondents with less than 5 years assign higher values to bundling/layering of services across multiple scales (mean $=4.33, S D=0.58$ ) and lower values to multi-level governance (mean $=4.00, S D=1.00)$. Conversely, the respondents with 5 or more years-long experience indicate a reverse order of importance of these aspects: multi-level governance (mean $=4.17, S D=0.79$ ) and bundling/layering of services across multiple scales (mean $=3.47, \mathrm{SD}=1.06)$.

The non-parametric Kruskal-Wallis test ( $a=0.05$ with a $p$-value from $0.307-$ bundling/layering of services across multiple scales to 0.893 - shared value for ecosystem services) showed no statistically significant difference between respondents with different years of expertise.

When observing the results for the scientific field, the average values assigned by forestry respondents are the following: shared value for ecosystem services ( $m e a n=4.27, S D=0.78$ ), multi-level governance 
(mean $=3.96, \mathrm{SD}=0.82$ ), and bundling/layering of services across multiple scales (mean $=3.65, \mathrm{SD}=$ 0.89). Similarly, for the respondents of other scientific fields the order of importance remains the same: share value for ecosystem services (mean $=4.62, S D=0.65$ ), multi-level governance ( mean $=4.58, S D=$ 0.51 ), and bundling/layering of services across multiple scales (mean $=3.31, S D=1.32$ ).

The Mann-Whitney non-parametric test showed a significant difference between the group of forestry respondents and respondents of other scientific fields, with group of forestry respondents shown to consider more important multi-level governance $(p<0.0001, a=0.05)$ while respondents of other scientific fields consider more important bundling/layering of services across multiple scales $(p=0.005, a=0.05)$.

The results concerning the environmental effectiveness of PES schemes (Q3.3) show that the most important factor in determining environmental effectiveness is the direct changes in land/resource management (additionality) with an average value of 4.11 ( $S D=0.83$ ), followed by the transaction and implementation costs with an average value of $3.67(\mathrm{SD}=1.28)$ and lastly the indirect effects of the scheme outside of contracted lands (spill-over effect) with an average value of $3.61(S D=0.89)$.

Observing the data by group of stakeholders (Table 3), it is important to highlight that for three groups (buyers, intermediaries, and knowledge providers) the most important factor is the direct changes in land/resource management, while for the sellers the most important factors are the transaction and implementation costs and the indirect changes, with the same mean value.

The non-parametric Kruskal-Wallis test shows $(a=0.05$ with a $p$-value from 0.284 - transaction and implementation costs to 0.869 - indirect changes) non-significant statistically differences among groups of stakeholders for the three factors determining the environmental effectiveness of PES schemes related to the water ecosystem services.

Regarding the years of expertise, the results show that respondents with less than 5 years of expertise consider the transaction and implementation costs (mean $=5.00, S D=0.0$ ) the most important factor, while respondents with more years of experience consider more important the direct changes in land/resource management. In particular, respondents with more than 15 years-long experience assign the highest value to this factor $($ mean $=4.23, S D=0.65)$.

The forestry respondents and those of other scientific fields (environmental/ecology sciences, water resource management) assign the same level of importance to the three factors: the direct changes in land/resource management (mean value of 4.00 and 4.15 respectively); the transaction and implementation costs (mean value of 3.58 and 3.85), and in last place the indirect changes (mean value of 3.58 and 3.62).

The results of the Kruskal-Wallis test indicate that there were no significant differences $(a=0.05)$ among the groups with different years of expertise. The results of the Mann-Whitney test $(a=0.05)$ indicated no differences between respondents belonging to different scientific fields, for all the three factors determining the environmental effectiveness of PES schemes. 


\section{Stakeholders' involvement in the PES schemes}

The results show that respondents believe that public authorities must play a key role in the PES schemes design and implementation (Q4.1). The majority thinks that public authority should be involved both as buyer and as regulator $(67.6 \%)$, while for the $21.6 \%$ of respondents public authority should play the role of regulator, and for the remaining $10.8 \%$ public authority should be involved in the PES schemes only as buyer. It is interesting to highlight that none of the respondents think that PES schemes should be implemented without public authority. These results suggest that Italian stakeholders consider public authorities (e.g., government, regions, provinces, and municipalities) as key actors not only in defining the legal framework of PES schemes, but also in stimulating the market as a buyer.

Despite some small differences, all groups of stakeholders think that public authority must be at the same time buyer and regulator in the PES schemes: particularly $83.3 \%$ of buyers and sellers, $68.8 \%$ of intermediaries, and $50.0 \%$ of knowledge providers. However, Fig. 7 shows that the latter two groups of stakeholders consider the role of public authority less pivotal compared to buyers and sellers: $20.0 \%$ of knowledge providers and $12.5 \%$ of intermediaries would limit the role of the public authority exclusively to that of a buyer.

Concerning respondents' opinion about the level of involvement of other stakeholders (single farmers or forest owners, environmental NGOs, various kind of associations, local community) in the PES schemes (Q4.2), the mean value given by respondents was used as a discriminant. The following thresholds were fixed: i) with the mean value less than 1.5 , level of information; ii) with the mean value between 1.5 and 2.4 (consultation); iii) with the mean value between 2.5 and 3.4 (collaboration/deliberation); and iv) with the mean value more than 3.4 (co-decision/coproduction).

The results show that respondents believe that the level of collaboration must be ensured to farmers'/forest owners' associations (mean value of $2.76, \mathrm{SD}=0.85$ ), while consultation must be ensured to environmental NGOs (mean $=2.34, \mathrm{SD}=1.05$ ) and fishing associations (mean $=2.29, \mathrm{SD}=0.98$ )

(Table 4). Comparing the opinions of different groups of stakeholders, the results show that farmers'/forest owners' associations are considered the key actor by all groups. Because of this they would be involved through a collaboration level in the decision-making process. The representatives of buyers, sellers, and intermediaries think that all other stakeholders should be involved through consultation, while representatives of knowledge providers believe that three kind of stakeholders should be involved through active collaboration: farmers'/forest owners' associations, environmental NGOs, and fishing associations. It is interesting to emphasize that according to the respondents' "information" is not a sufficient level of involvement in the PES schemes, but more active involvement of all stakeholders is needed.

\section{Discussion}


In Italy, the PES schemes have been developing rapidly in the past decades to overcome the limits of regulatory instruments (command-and-control policy). Recently, the new Italian Forest Act (Legislative Decree ${ }^{\circ}{ }^{34}$ /2018) promotes the Payment for Ecosystem Services (PES) generated by sustainable forest management activities finalized at informing and supporting landowners, managers, and beneficiaries (art.7). The general provisions of the Legislative Decree $n^{\circ} 34 / 2018$ are in line with the objectives of the new European Union (EU) Forest Strategy (2013) aimed at promoting and enhancing the ecosystem services of European forests. In this context, many projects and proposals based on innovative tools of environmental governance are rapidly developing in Italy such as the Italian Network of Ecosystem Service Partnership and some PES schemes implemented at regional and local level (Pellegrino et al. 2016; Marino and Pellegrino 2018). In particular, Gatto et al. (2009) for the Italian context described three main types of PES: (1) water tariffs (payments from water end-users are used by service suppliers for forest management interventions aimed to service provision); (2) wild mushroom permits (payments received by the sale of mushroom permits are used for forest tending operations); (3) adventure parks (payments received from tickets are used for forest management interventions aimed at providing the recreational activity). Recently, Marino and Pellegrino (2018) described in detail 33 PES schemes in 19 Italian Natura 2000 sites - located in seven Italian regions (Lombardy, Emilia-Romagna, Marche, Campania, Basilicata, Calabria, Sicily) - emphasizing the role of this market-based instrument to improve management effectiveness in biodiversity conservation.

In the PES schemes design and implementation, several authors have shown that the four main aspects which must be taken into consideration are: i) biophysical assessment and economic evaluation of ecosystem services provided before and after environmental measures (De Meo et al. 2018; Börner et al. 2017); ii) achieving environmental and socio-economic outcomes of PES schemes (Yang et al. 2018; Adhikari and Agrawal 2013); iii) involving landowners and other stakeholders in the decision-making process (Reed et al. 2017; Báliková et al. 2020); and iv) institutional framework of PES schemes (Matzdorf et al. 2013; Vatn 2010).

In the present study, a sample of Italian stakeholders was consulted with the aim of bringing out their opinions and points of view on the relationship between forests and water resources and water-related PES schemes. The sample of stakeholders involved in the survey emphasized the close link between forests and water resources with special regard to two categories of ecosystem services provided by forests: regulating and supporting services. Stakeholders believe that forests play a key role in providing two WES included in the regulating services - soil erosion and surface runoff reduction - and one included in the supporting services, that means the maintenance of habitats for several species. Sustainable forest management (SFM) practices can improve the provision of WES, but at the same time - as pointed out by $78 \%$ of the sample - can generate trade-offs between WES. In particular, according to stakeholders' opinions, the main trade-offs are between supporting and cultural services, and between provisioning and regulating services. In the international literature, some studies highlighted that forest management practices focused on provisioning services can generate a decrease in the flow of others ecosystem services such as regulating and supporting services (Grêt-Regamey et al. 2013; Biber et al. 2015; Marchi et al. 2018). In addition, Deniz and Paletto (2018) pointed out that Italian and Turkish 
experts think that intensive forest management can give rise to negative effects on some WES such as surface runoff, water infiltration, risk of floods and landslides, use of groundwater for quality drinking water, and sedimentation in streams. The trade-offs between WES are a potential cause of conflict between groups of stakeholders with different and opposing interests as pointed out by Stosch et al. (2019). To reduce the conflicts between stakeholders, a timely and inclusive participatory process must be developed by the promoters. According to our sample ( $68 \%$ of respondents), public authority should play a dual role (Boisvert et al. 2013): as a legal driver defining the regulatory framework and as buyer influencing the demand for ecosystem services and providing a financial source for PES development. This approach is in line with the school of thought that considers public authority responsible to ensure natural capital protection and provision of ecosystem services for the well-being of society (Jenkins et al. 2004). In order to pursue this objective, public authority has a wide range of regulatory and non-regulatory instruments to be adopted (Gómez-Baggethun and Muradian 2015; Pirard and Lapeyre 2014; Pirard 2012). Concerning the other stakeholders, the respondents to the present survey indicated that all social actors must be at least consulted including citizens, while some key social actors - farmers'/forest owners' associations, environmental NGOs, fishing associations - should be actively involved. The stakeholders' involvement in designing and implementing PES schemes is a key point to improve the quality of the environmental decisions focused on ecosystem services (Sattler and Matzdorf 2013; Reed et al. 2017).

In the international literature, some authors pointed out that PES schemes are more efficient than command-and-control policy (Engel et al. 2008). The PES schemes' efficiency is strictly related to their ability to internalize the environmental externalities (Muradian et al. 2010). However, respondents of the present survey have a different opinion: $32.4 \%$ of them consider the PES schemes more efficient, $35.2 \%$ of them consider the regulatory instruments more efficient, while the remaining $32.4 \%$ attributes equal efficiency to the two instruments.

Regarding the PES schemes implementation, the majority of respondents agree on the importance of a shared value for ecosystem services among all institutional and non-institutional actors and a multi-level governance able to incorporate traditional and local knowledge in the payment mechanisms. Nevertheless, according to Irvine et al. (2016) the practical problem is how to include shared value for ecosystem services and traditional and indigenous knowledge of local community in decision-making process.

Finally, it is interesting to emphasize that the stakeholders involved in this survey think that direct changes (additionality) in forest management activities due to the PES schemes can be considered the key factor to determine the environmental effectiveness of this market-based instrument. According to Börner et al. (2017) the potential problem with direct changes occurs when recipient of the payment would meet the program goals even without any changes of land use or forest management.

\section{Conclusions}


The Payment for Ecosystem Services (PES) schemes are innovative market-based instruments proposed all over the world to improve the provision of ecosystem services and the maintenance of natural capital. During the design and implementation of PES schemes, the stakeholders' involvement is a fundamental aspect to reduce social frictions and to increase broad acceptance of these voluntary instruments. However, some stakeholders directly involved in the PES schemes implementation - such as landowners from the supply side and private companies and eventually public institutions from the demand side must be engaged at a level of collaboration or co-decision. The intermediaries and knowledge providers should be having the role of facilitators of the process providing knowledge, skills and information, while the other stakeholders should be consulted, at least to know their points of view and needs. Therefore, stakeholders' preferences and opinions are key information to reduce conflicts among groups with opposing interests and to facilitate the implementation success of these market-based instruments.

In this context, the present study identifies a priority list of WES to maintain and improve though the forest management and afforestation/reforestation practices. The regulating services - with special regard to soil erosion and surface runoff reduction - are considered the most important WES category, while the cultural services (aesthetic landscape conservation and recreation activities) are considered of marginal importance. Regulating services as well as supporting services should be the main categories of WES to be considered in the definition and implementation of suitable forest management practices. Intensive forest management practices aimed to increase timber and bioenergy production - e.g., clearcutting and removal of wood residues for bioenergy production - can produce negative impacts on many regulating (soil erosion and water regulation) and supporting services (habitats and micro-habitats for animal species). Conversely, close-to-nature management practices based on lighter variants of the shelterwood method can have positive impacts on several WES.

From the methodological point of view, the main advantages of the proposed method used to investigate stakeholders' opinions are simplicity and ease of data gathering. The use of a semi-structured questionnaire has the advantage to provide comparable data, but at the same time it is unable to investigate in detail some key topics. Conversely, the main disadvantages are related to the difficulty to identify a significant sample of respondents and to the possible low response rates related to the online administration system.

The future steps of the study will be to investigate in detail some key topics - such as success and failure factors of PES schemes, network analysis of relationships of social actors involved in the PES schemes - through in-depth interviews with experts and a sample of privileged stakeholders.

\section{References}

Adhikari B, Agrawal A (2013) Understanding the social and ecological outcomes of PES projects: A review and an analysis. Conserv Soc 11:359.

Alonso JA, Lamata, MT (2006) Consistency in the Analytic Hierarchy Process: A new approach. Int J Uncertain 14:445-459. 
Andersen MS, Sprenger RU (2000) Market-based Instruments for Environmental Management. Politics and Institutions. Edward Elgar, Cheltenham, Northampton.

Báliková K, Červená T, De Meo I, De Vreese R, Deniz T, El Mokaddem A, Kayacan B, Larabi F, Lībiete Z, Lyubenova M, Pezdevšek Malovrh Š, Potočki K, Pelyukh O, Rugani B, Sarvasova Z, Šálka J, Stevanov M, Stojnic S, Jarský V, Vuletić D, Zahvoyska L, Paletto A (2020) How Do Stakeholders Working on the Forest-Water Nexus Perceive Payments for Ecosystem Services? Forests 11:12.

Biber P, Borges J, Moshammer R, Barreiro S, Botequim B, Brodrechtova Y, Brukas V, Chirici G, CorderoDebets R, Corrigan E, Eriksson O, Favero M, Galev E, Garcia-Gonzalo J, Hengeveld G, Kavaliauskas M, Marchetti M, Marques S, Mozgeris G, Navratil R, Nieuwenhuis M, Orazio C, Paligorov I, Pettenella D, Sedmak R, Smrecek R, Stanislovaitis A, Tome M, Trubins R, Tucek J, Vizzarri M, Wallin I, Pretzsch H, Sallnäs $O$ (2015). How sensitive are ecosystem services in European forest landscapes to silvicultural treatment? Forests 6:1666-1695.

Birgé HE, Allen CR, Garmestani AS, Pope KL (2016) Adaptive management for ecosystem services. J Environ Manage 183:343-352.

Boisvert V, Méral P, Froger G (2013) Market-Based Instruments for Ecosystem Services: Institutional Innovation or Renovation? Soc Natur Resour 26:1122-1136.

Börner J, Baylis K, Corbera E, Ezzine-de-Blas D, Honey-Rosés J, Persson UM, Wunder S (2017) The effectiveness of payments for environmental services. World Dev 96:359-374.

Bréthaut C (2016) River Management and Stakeholders' Participation: The case of the Rhone River, a fragmented institutional setting. Environ Policy Gov 26:292-305.

Calder I, Hofer T, Vermont S, Warren P (2007) Towards a new understanding of forests and water. Unasylva 229:3-10.

Creed I, Masiero M, Pettenella D, Libert B (2018) The enabling environment for forests and water. In: UNECE (ed), Forests and Water. Valuation and payments for forest ecosystem services. United Nationas Economic Commission for Europe, Geneva, pp 14-29.

De Meo I, Cantiani M, Ferretti F, Paletto A (2018) Qualitative Assessment of Forest Ecosystem Services: The Stakeholders' Point of View in Support of Landscape Planning. Forests 9:465.

Deniz T, Paletto A (2018) Effects of bioenergy production on environmental sustainability: a preliminary study based on expert opinions in Italy and Turkey. J For Res 29:1611-1626.

Diswandi D (2017) A hybrid Coasean and Pigouvian approach to Payment for Ecosystem Services Program in West Lombok: Does it contribute to poverty alleviation? Ecosyst Serv 23:138-145. 
Engel S, Pagiola S, Wunder S (2008) Designing payments for environmental services in theory and practice: Anoverview of theissues. Ecol Econ 65:663-674.

Esse C, Santander-Massa R, Encina-Montoya F, De los Ríos P, Fonseca D, Saavedra P (2019). Multicriteria spatial analysis applied to identifying ecosystem services in mixed-use river catchment areas in south central Chile. For Ecosyst 6:25.

Gatto P, Pettenella D, Secco L (2009) Payments for forest environmental services: organisational models and related experiences in Italy. IFores 2:133-139.

Gómez-Baggethun E, Muradian R (2015) In markets we trust? Setting the boundaries of market-based instruments in ecosystem services governance. Ecol Econ 117:217-224.

Grêt-Regamey A, Brunner S, Altwegg J, Christen M, Bebi P (2013) Integrating expert knowledge into mapping ecosystem services trade-offs for sustainable forest management. Ecol Soc 18:3.

Hanson C, Talberth J, Yonavjak L (2011) Forests for Water: Exploring Payments for Watershed Services in the U.S. South, WRI Issue Brief, Southern Forests for the Future Incentives Series, Issue Brief: 2, World Resources Institute.

Herwig U (2008) Public participation in the establishment and management of the Natura 2000 network: Legal framework and administrative practices in selected member states. UFZ-Diskussionpapiere 1/2008, Helmholtz Centre for Environmental Research (UFZ).

Huang M, Zhang L, Gallichand J (2003) Runoff responses to afforestation in a watershed of the Loess Plateau, China. Hydrol Process 17:2599-2609.

Irvine KN, O'Brien L, Ravenscroft N, Cooper N, Everard M, Fazey I, Reed MS, Kenter JO (2016) Ecosystem services and the idea of sharedvalues. Ecosyst Serv 21:184-193.

Jenkins M, Scherr SJ, Inbar M (2004) Markets for Biodiversity Services: Potential Roles and Challenges. Environment 46:32-42.

Kneeshow DD, Leduc A, Drapeau P, Gauthier S, Paré D, Carignan R, Doucet R, Bouthillier L, Messier C (2000) Development of integrated ecological standards of sustainable forest management at an operational scale. Forest Chron 76:481-493.

Leonardi A, Pettenella D (2018) Payments for Forest-related Watershed Ecosystem Services. In: UNECE (ed), Forests and Water. Valuation and payments for forest ecosystem services. United Nationas Economic Commission for Europe, Geneva, pp 40-59.

Marchi M, Paletto A, Cantiani P, Bianchetto E, De Meo I (2018) Comparing Thinning System Effects on Ecosystem Services Provision in Artificial Black Pine (Pinus nigra J. F. Arnold) Forests. Forests 9:188. 
Marino D, Pellegrino D (2018) Can Payments for Ecosystem Services improve the management of Natura 2000 sites? A contribution to explore their role in Italy. Sustainability 10:665.

Matzdorf B, Sattler C, Engel S (2013) Institutional frameworks and governance structures of PES schemes. For Pol Econ 37:57-64.

MEA (2005) Millennium Ecosystem Assessment, Ecosystems and Human Well-Being: Current States and Trends. Island Press, Washington DC.

Muradian R, Corbera E, Pascual U, Kosoy N, May PH (2010) Reconciling theory and practice: An alternative conceptual framework for understanding payments for environmental services. Ecol Econ 69:1202-1208.

Nisbet T, Silgram M, Shah N, Morrow K, Broadmeadow S (2011) Woodland for Water: Woodland measures for meeting Water Framework Directive objectives. Forest Research Monograph, 4, Forest Research, Surrey, p 156.

Paletto A, Hamunen K, De Meo I (2015) The social network analysis to support the stakeholder analysis in participatory forest planning. Soc Natur Resour 28:1108-1125.

Pascual U, Muradian R, Rodríguez LC, Duraiappah A (2010) Exploring the links between equity and efficiency in payments for environmental services: A conceptual approach. Ecol Econ 69:1237-1244.

Pellegrino D, Schirpke U, Marino D (2016) How to support the effective management of Natura 2000 sites? J Environ Plan Man 60:383-398.

Pirard R (2012) Market-based instruments for biodiversity and ecosystem services: A lexicon. Environ Sci Policy 19:59-68.

Pirard R, Lapeyre R (2014) Classifying market-based instruments for ecosystem services: A guide to the literature jungle. Ecosyst Serv 9:106-114.

Pukkala T (2016) Which type of forest management provides most ecosystem services? For Ecosyst 3:9.

Reed MS, Allen K, Attlee A, Dougill AJ, Evans KL, Kenter JO, Hoy J, McNab D, Stead SM, Twyman C, Scott AS, Smyth MA, Stringer LC, Whittingham MJ (2017) A place-based approach to payments for ecosystem services. Global Environ Chang 43:92-106.

Saaty RW (1987) The Analytic Hierarchy Process - what i tis and how i tis used. Math Model 3-5:161176.

Saaty RW (2003) Decision-making with the AHP: Why is the principal eigenvector necessary. Eur J Oper Res 145:85-91. 
Saenz L, Mulligan M (2013) The role of Cloud Affeted Forests (CAFs) on water inputs to dams. Ecosyst Serv 5:69-77.

Salzman J (2005) The promise and perils of payments for ecosystem services. Int J Innov Sust Develop $1(1-2): 5-20$.

Sattler C, Trampnau S, Schomers S, Meyer C, Matzdorf B (2013). Multi-classification of payments for ecosystem services: How do classification characteristics relate to overall PES success? Ecosyst Serv 6:31-45.

Sattler C, Matzdorf B (2013) PES in a nutshell: From definitions and origins to PES in practice Approaches, design process and innovative aspects. Ecosyst Serv 6:2-11.

Sharma E, Xu J (2007) Land-use, landscape management and environmental services in the Mountain Mainland Asia. Trop Ecol 48:129-136.

Smith M, de Groot D, Bergkamp GP (2006) Establishing payments for watershed services. International Union for Conservation of Nature (IUCN), Gland p 109.

Smith S, Rowcroft P, Everard M, Couldrick L, Reed M, Rogers H, Quick T, Eves C, White C (2013) Payments for ecosystem services: a best practice guide. Defra, London, $\mathrm{p} 85$.

Stosch KC, Quilliam RS, Bunnefeld N, Oliver DM (2019) Quantifying stakeholder understanding of an ecosystem service trade-off. Sci Total Environ 651:2524-2534.

Stupak I, Lattimore B, Titus BD, Smith CT (2011) Criteria and indicators for sustainable forest fuel production and harvesting: A review of current standards for sustainable forest management. Biomass Bioenerg 35:3287-3308.

Tacconi L (2012) Redefining payments for environmental services. Ecol Econ 73:29-36.

TEEB (2010) The Economics of Ecosystem Services and Biodiversity: Ecological and Economic Foundations, An output of TEEB: The Economics of Ecosystems and Biodiversity, Earthscan, Cambridge. van der Salm C, van der Gon HD, Wieggers R, Bleeker A, van den Toorn A (2006) The effect of afforestation on water recharge and nitrogen leaching in The Netherlands. For Ecol Manag 221:170-182.

van Dijk AIJM, Keenan RJ (2007) Overview. Planted forests and water in perspective. For Ecol Manag 251:1-9.

Varvasovszky Z, Brugha R (2000) A stakeholder analysis. Health Policy Plann15:338-345.

Vatn A (2010) An institutional analysis of payments for environmental services. Ecol Econ 69:1245-1252. 
Wunder S, Thorsen BJ (2014) Quantifying water externalities from forests. In: Thoresen BJ, Mavsar R, Tyrväinen L, Prokofieva I, Stenger A (eds), The Provision of Forrest Ecosystem Services. Volume I: Quantifying and valuing non-marketed ecosystem services. What Science Can Tell Us. European Forest Institute (EFI), Joensuu, pp 21-25.

Wunder S (2015) Revisiting the concept of payments for environmental services. Ecol Econ 117:234-43.

Yang H, Yang W, Zhang J, Connor T, Liu J (2018) Revealing path ways from payments for ecosystem services to socioeconomic outcomes. Sci Adv 4:eaao6652.

\section{Tables}

Table 1 Distribution of respondents by targeted group, expertise, and scientific field (\%)

\begin{tabular}{lcccc}
\hline Characteristics/Targeted group & $\mathrm{B}(n=6)$ & $\mathrm{S}(n=6)$ & $\mathrm{I}(n=17)$ & $\mathrm{K}(n=10)$ \\
\hline Years of expertise & 0.0 & 0.0 & 11.8 & 10.0 \\
Less than 6 year & 16.7 & 16.7 & 5.8 & 10.0 \\
6-10 years & 33.3 & 0.0 & 0.0 & 30.0 \\
11-15 years & 50.0 & 83.0 & 82.4 & 50.0 \\
More than 15 years & & & & \\
Scientific field & & & & \\
Forestry & 83.3 & 100.0 & 64.7 & 40.0 \\
Environmental/ecology science & 0.0 & 0.0 & 35.3 & 40.0 \\
Water resource management & 16.7 & 0.0 & 0.0 & 20.0 \\
\hline
\end{tabular}

$\mathrm{B}=$ Buyers, $\mathrm{S}=$ Sellers, $\mathrm{I}=$ Intermediaries, $\mathrm{K}=$ Knowledge providers

Table 2 Priority scores ( $w$ ) for the categories of ecosystem services by group of stakeholders

\begin{tabular}{lccccc}
\hline Category/Priority score & $\mathrm{B}(n=6)$ & $\mathrm{S}(n=6)$ & $\mathrm{I}(n=17)$ & $\mathrm{K}(n=10)$ & Total $(n=39)$ \\
\hline Provisioning services & 0.2964 & 0.3890 & 0.2730 & 0.2264 & 0.2810 \\
Regulating services & 0.2964 & 0.2697 & 0.3369 & 0.3814 & 0.3328 \\
Supporting services & 0.2831 & 0.1707 & 0.2399 & 0.2202 & 0.2307 \\
Cultural services & 0.1242 & 0.1707 & 0.1502 & 0.1720 & 0.1555 \\
CI & 0.0041 & 0.0065 & 0.0025 & 0.0094 & 0.0037 \\
$C R$ & 0.0045 & 0.0072 & 0.0028 & 0.0104 & 0.0041 \\
\hline
\end{tabular}


In bold the highest priority score for group of stakeholders

$\mathrm{B}=$ Buyers, $\mathrm{S}=$ Sellers $\mathrm{I}=$ Intermediaries, $\mathrm{K}=$ Knowledge providers

Table 3 Level of importance (mean and st.dev.) of environmental effectiveness factors of PES schemes

\begin{tabular}{|c|c|c|c|}
\hline Factors & Transaction and implementation costs & Direct changes & Indirect changes \\
\hline \multicolumn{4}{|l|}{ Groups of stakeholders } \\
\hline Buyers $(n=6)$ & $3.17(1.17)$ & $4.17(0.75)$ & $3.50(1.05)$ \\
\hline Sellers $(n=6)$ & $3.83(0.75)$ & $3.67(0.52)$ & $3.83(0.75)$ \\
\hline Intermediaries $(n=17)$ & $4.13(1.09)$ & $4.19(0.91)$ & $3.63(0.72)$ \\
\hline Knowledge providers $(n=10)$ & $3.50(1.35)$ & $4.20(0.92)$ & $3.50(1.18)$ \\
\hline \multicolumn{4}{|l|}{ Years of expertise } \\
\hline Less than 5 years $(n=3)$ & $5.00(0.00)$ & $4.00(1.73)$ & $4.00(1.00)$ \\
\hline $5-10$ years $(n=5)$ & $3.80(1.30)$ & $3.80(1.10)$ & $3.40(1.14)$ \\
\hline $11-15$ years $(n=4)$ & $3.00(1.83)$ & $3.75(0.96)$ & $3.50(1.29)$ \\
\hline More than 15 years $(n=27)$ & $3.73(1.00)$ & $4.23(0.65)$ & $3.62(0.80)$ \\
\hline \multicolumn{4}{|l|}{ Scientific field } \\
\hline Forestry $(n=26)$ & $3.58(1.31)$ & $4.00(1.04)$ & $3.58(1.08)$ \\
\hline Other scientific fields $(n=13)$ & $3.85(1.08)$ & $4.15(0.73)$ & $3.62(0.80)$ \\
\hline
\end{tabular}

In bolt the most important factor by group of respondents

Table 4 Level of involvement of stakeholders in the PES schemes according to respondents' opinions (mean and st.dev.) 


\begin{tabular}{|c|c|c|c|c|c|}
\hline Stakeholders involvement/Group & $\mathrm{B}(n=6)$ & $\mathrm{S}(n=6)$ & I $(n=17)$ & $\mathrm{K}(n=10)$ & Total $(n=39)$ \\
\hline Single farmers & $2.00(1.26)$ & $1.88(0.86)$ & $1.50(1.08)$ & $2.33(1.03)$ & $1.89(1.01)$ \\
\hline Single forest owners & $2.00(1.26)$ & $1.94(0.97)$ & $1.50(1.08)$ & $2.33(1.03)$ & $1.92(1.05)$ \\
\hline Environmental NGOs & $2.00(1.10)$ & $2.35(0.93)$ & $2.20(1.23)$ & $2.67(0.82)$ & 2.34 (1.05) \\
\hline Fishing associations & $2.17(1.33)$ & $2.24(0.90)$ & $2.50(1.27)$ & $2.33(0.52)$ & $2.29(0.98)$ \\
\hline Farmers/forest owners associations & $2.83(1.17)$ & $2.71(0.77)$ & $2.90(0.99)$ & $2.67(0.52)$ & $2.76(0.85)$ \\
\hline Tourism associations & $1.67(0.82)$ & $1.94(0.75)$ & $2.00(1.05)$ & $2.67(0.82)$ & $2.05(0.87)$ \\
\hline Citizens (local community) & $1.83(0.75)$ & $2.06(1.03)$ & $1.80(1.40)$ & $1.83(1.33)$ & $1.95(1.11)$ \\
\hline
\end{tabular}

In bolt the two kind of stakeholders who should be involved with the highest level of involvement.

\section{Figures}

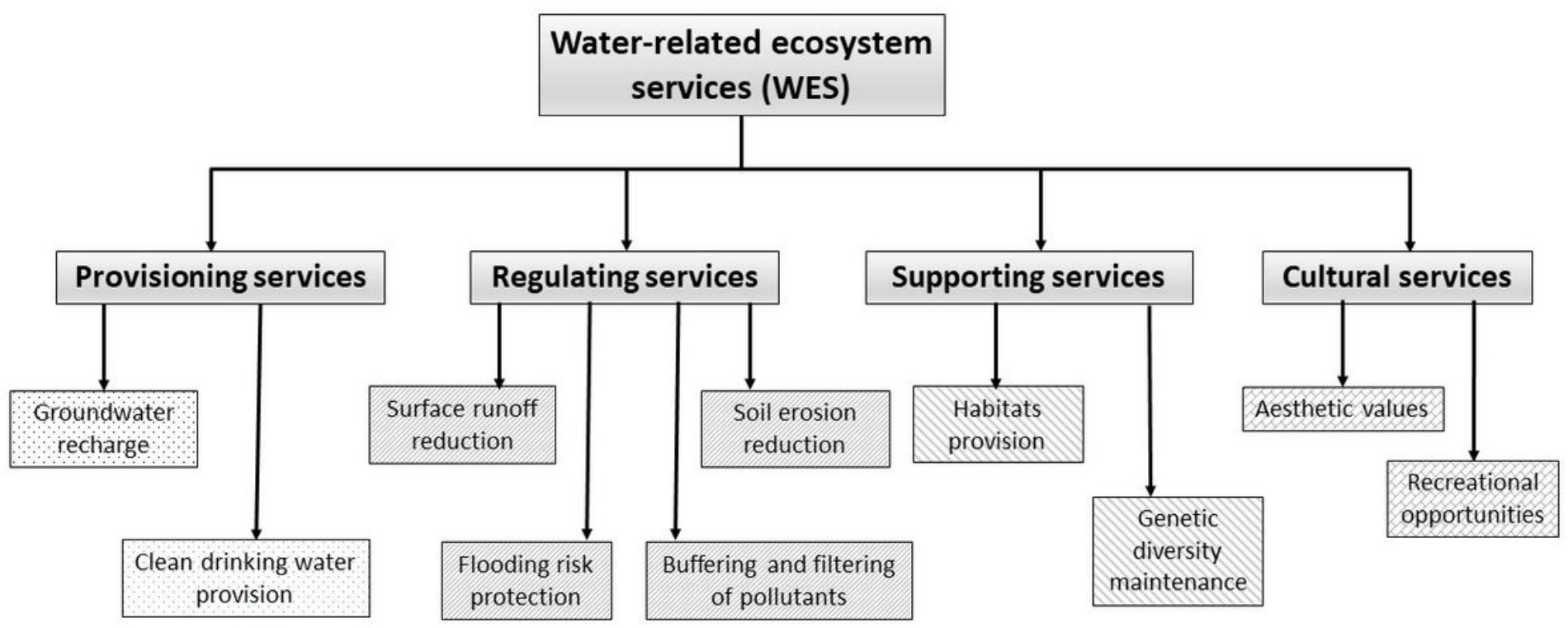

\section{Figure 1}

Watershed-related ecosystem services (WES) considered in the survey. 


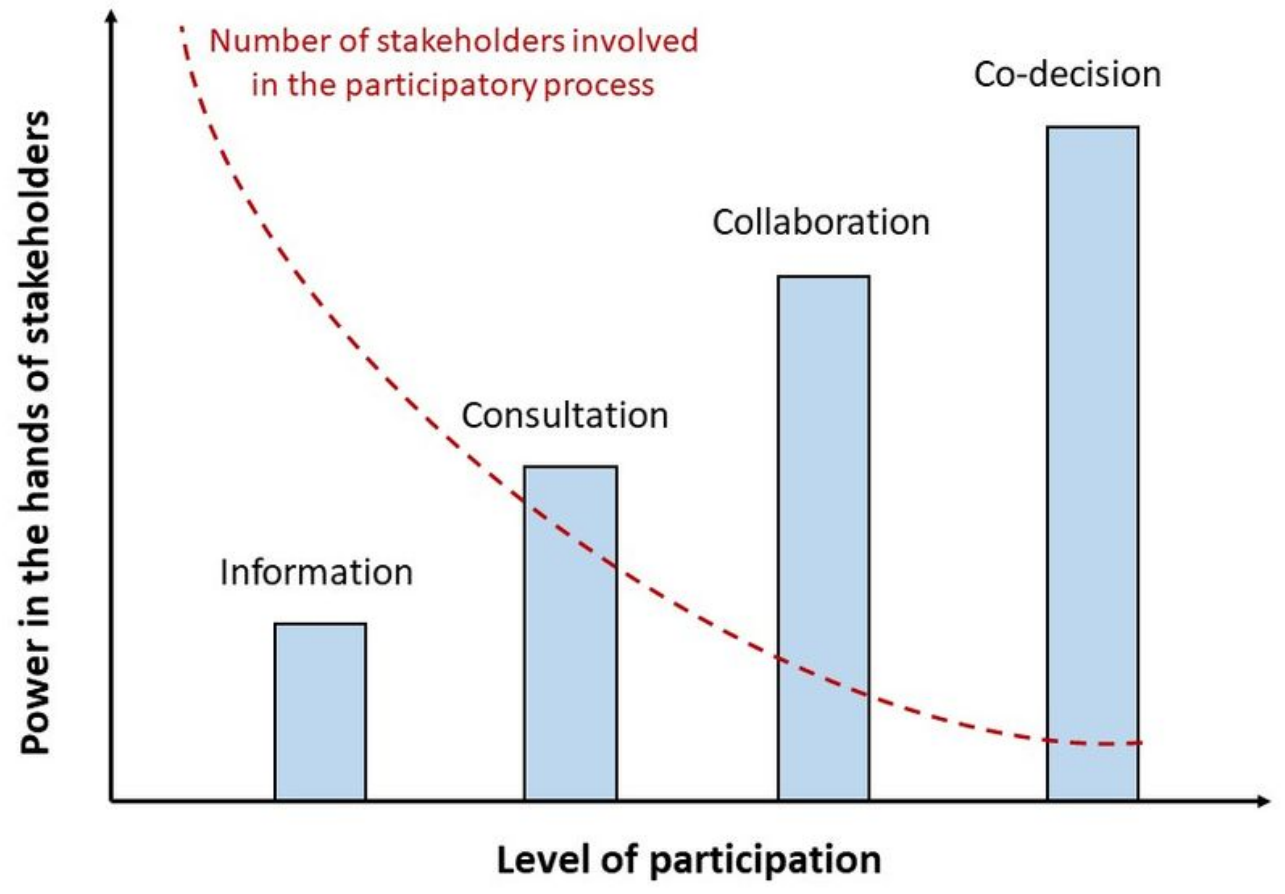

Figure 2

Four levels of involvement of the stakeholders in the decision-making process. 


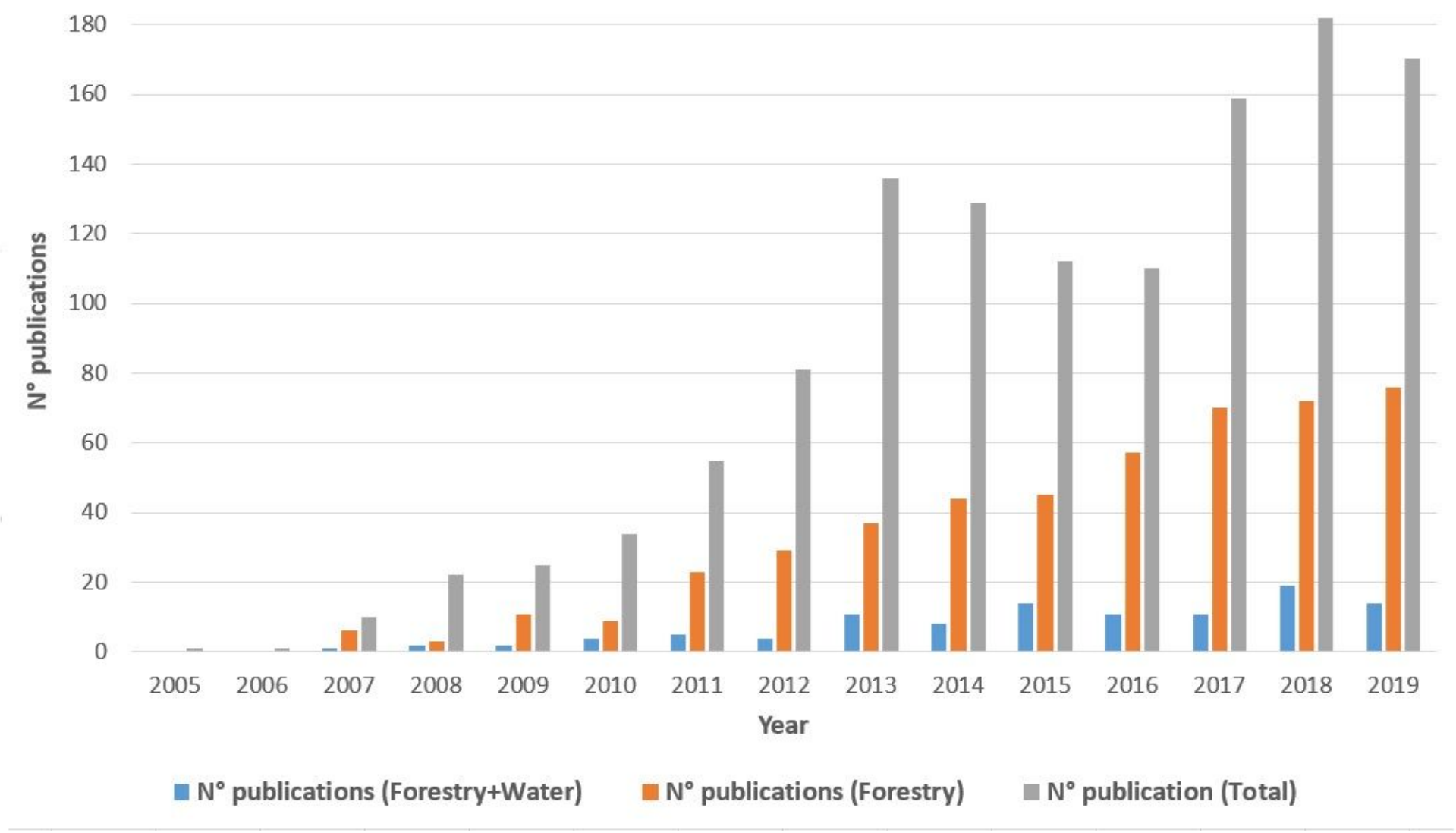

Figure 3

Trend of peer-reviewed publications on Payment for Ecosystem Services (PES) in the Scopus database (period 2005-2019). 


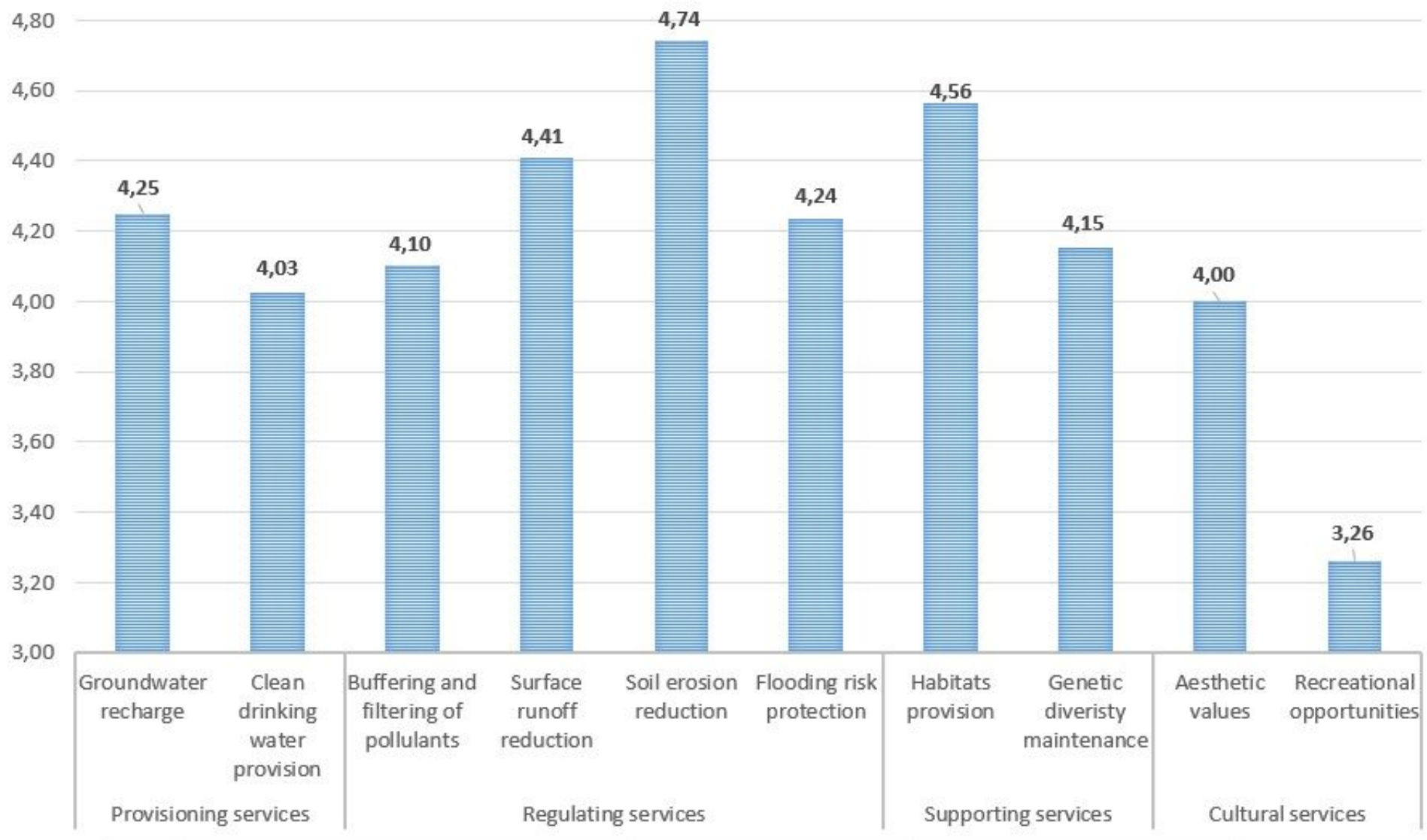

\section{Figure 4}

Ranking of WES provided by forests (mean value) aggregated by category of ecosystem services. 


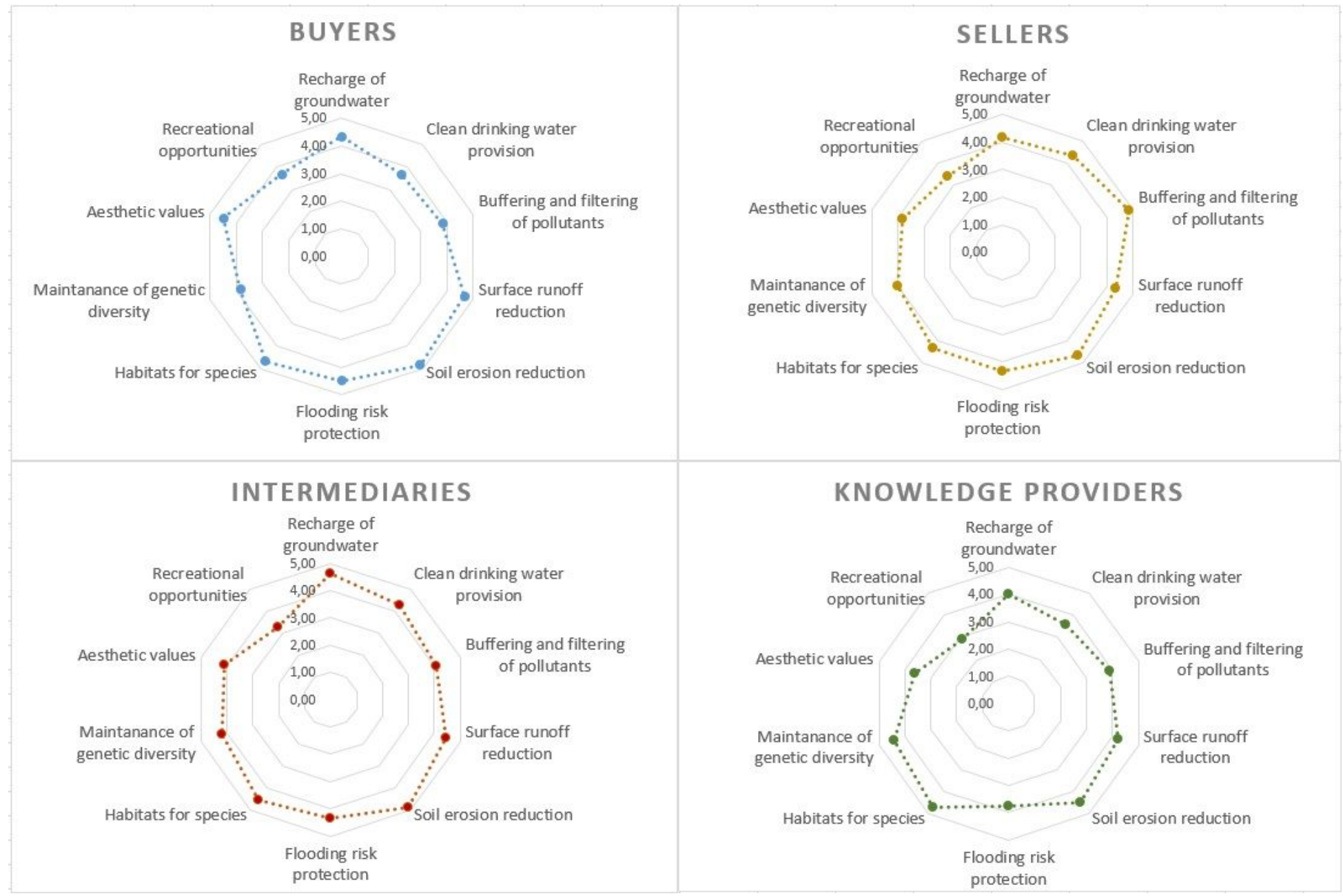

\section{Figure 5}

Ranking of WES provided by forests (mean value) by group of stakeholders

Multi-governance

\section{Figure 6}

Box-plots of level of importance of three key aspects in the PES schemes implementation by group of stakeholders 


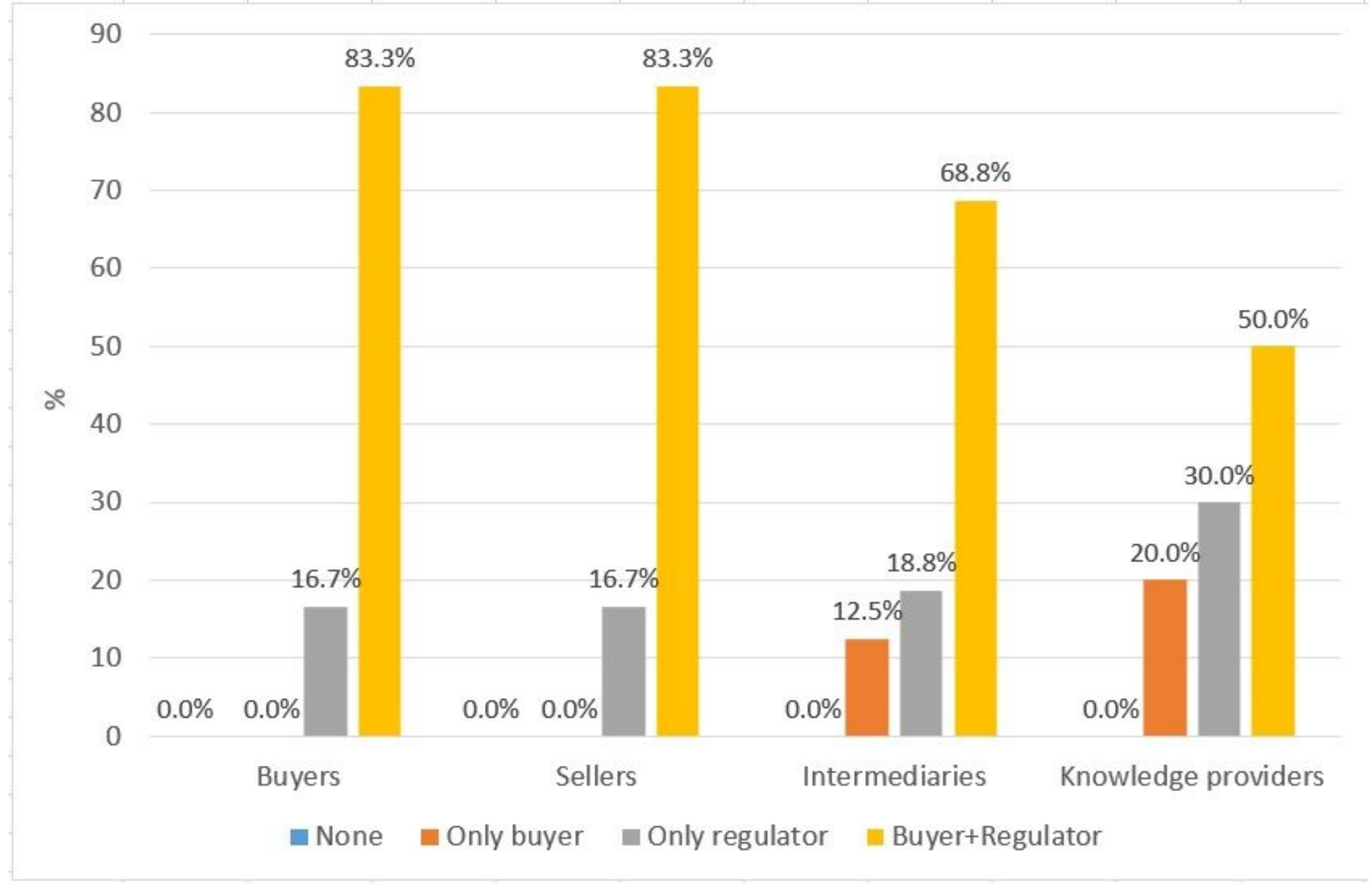

\section{Figure 7}

The role of the public authority in the design and implementation of PES schemes by group of stakeholders.

\section{Supplementary Files}

This is a list of supplementary files associated with this preprint. Click to download.

- Annex1.docx 